\title{
A case-control study of malignant and non-malignant respiratory disease among employees of a fibreglass manufacturing facility. II Exposure assessment
}

\author{
Leonard Chiazze Jr, Deborah K Watkins, Cheryl Fryar, Joseph Kozono
}

\begin{abstract}
A case-control study of malignant and nonmalignant respiratory disease among employees of the Owens-Corning Fiberglas Corporation's Newark, Ohio plant was undertaken. The aim was to determine the extent to which exposures to substances in the Newark plant environment, to non-workplace factors, or to a combination may play a part in the risk of mortality from respiratory disease among workers in this plant. A historical environmental reconstruction of the plant was undertaken to characterise the exposure profile for workers in this plant from its beginnings in 1934 to the end of 1987. The exposure profile provided estimates of cumulative exposure to respirable fibres, fine fibres, asbestos, talc, formaldehyde, silica, and asphalt fumes. Employment histories from Owens-Corning Fiberglas provided information on employment characteristics (duration of employment, year of hire, age at first hire) and an interview survey obtained information on demographic characteristics (birthdate, race, education, marital state, parent's ethnic background, and place of birth), lifetime residence, occupational and smoking histories, hobbies, and personal and family medical history. Matched, unadjusted odds ratios (ORs) were used to assess the association between lung cancer or non-malignant respiratory disease and the cumulative exposure history, demographic characteristics, and employment variables. Only the smoking variables and employment characteristics (year of hire and
\end{abstract}

Division of Biostatistics and Epidemiology, Department of Community and Family Medicine, Georgetown University School of Medicine, Washington, DC 20007, USA

L Chiazze, D K Watkins, C Fryar, J Kozono age at first hire) were statistically significant for lung cancer. For non-malignant respiratory disease, only the smoking variables were statistically significant in the univariate analysis. Of the variables entered into a conditional logistic regression model for lung cancer, only smoking (smoked for six months or more $v$ never smoked: $O R=26 \cdot 17,95 \%$ confidence interval (95\% CI) $3 \cdot 316-206 \cdot 5)$ and age at first hire (35 and over $v$ less than 35: $O R=0 \cdot 244$, $95 \%$ CI $0.083-0.717$ ) were statistically significant. There were, however, increased ORs for year of employment (first hired before $1945 v$ first hired after 1945: $O R=1.944,95 \%$ CI $0 \cdot 850-4 \cdot 445$ ), talc (cumulative exposure $>1000$ fibres/ml days $v$ never exposed: $O R=1 \cdot 355$, 95\% CI 0.407-4.515), and asphalt fumes (cumulative exposure $>0.01 \mathrm{mg} / \mathrm{m}^{3}$ days $v$ never exposed: $\quad O R=1 \cdot 131, \quad 95 \% \quad$ CI $0 \cdot 468-2 \cdot 730$ ). For non-malignant respiratory disease, only the smoking variable was significant in the conditional logistic regression analysis $(O R=2 \cdot 637,95 \%$ CI $1 \cdot 146-6 \cdot 069)$. There were raised ORs for the higher cumulative exposure categories for respirable fibres, asbestos, silica, and asphalt fumes. For both silica and asphalt fumes, ORs were more than double the reference groups for all exposure categories. A limited number of subjects were exposed to fine fibres. The scarcity of cases and controls limits the extent to which analyses for fine fibre may be carried out. Within those limitations, among those who had worked with fine fibre, the unadjusted, unmatched $O R$ for lung cancer was $1.0(95 \%$ CI 0.229-4.373) and for non-malignant respiratory disease, the $O R$ was $1.5(95 \%$ CI $0 \cdot 336-6 \cdot 702)$. The unadjusted OR for lung cancer for exposure to fine fibre was consistent with that for all respirable fibres and does not suggest an association. For non-malignant respiratory disease, the unadjusted $O R$ for fine fibre was opposite in direction from that 
for all respirable fibres. Within the limitations of the available data on fine fibre, there is no suggestion that exposure to fine fibre has resulted in an increase in risk of lung cancer. The increased $O R$ for non-malignant respiratory disease is inconclusive. The results of this investigation clearly indicate that for this population, in this place and time, neither respirable fibres nor any of the substances investigated as part of the plant environment are statistically significant factors for lung cancer risk although there are increased ORs for exposure to talc and asphalt fumes. Smoking is the most important factor in risk for lung cancer in this population. The situation is less clear for non-malignant respiratory disease. Unlike lung cancer, non-malignant respiratory disease represents a constellation of outcomes and not a single well defined end point. Although smoking was the only statistically significant risk factor for non-malignant respiratory disease in this analysis, the ORs for respirable fibres, asbestos, silica, and asphalt fumes were greater than unity for the highest exposure categories. Although the raised ORs for these substances may represent the results of a random process, they may be suggestive of an increased risk and require further investigation.

(British fournal of Industrial Medicine 1993;50:717-725)

Recently we reported the results of the personal interview survey portion of a case-control study of malignant and non-malignant respiratory disease among employees of the Owens-Corning Fiberglas Newark, Ohio plant, the oldest and largest fibreglass manufacturing facility in the United States. ${ }^{1}$ Analysis of these data showed that smoking is the most important non-workplace factor for risk of lung cancer in this group of workers although it may not play as important a part for non-malignant respiratory disease as for lung cancer.

As well as the interview survey, we undertook a historical environmental reconstruction of the Newark plant in cooperation with Owens-Corning Fiberglas. The aim was to reconstruct the environment of the plant from its beginnings as a fibreglass manufacturing facility in 1934 to the end of 1987, the year the reconstruction was undertaken. Fibreglass production began as a joint venture between Owens-Illinois and Corning Glass in 1934 and the plant has been operated by Owens-Corning Fiberglas since the founding of the company in 1938. The historical environmental reconstruction was designed to characterise the working environment at Newark and to provide a basis for placing an employee in a specific location in the plant, during a particular calendar time, and enumerating exposures to fibrous glass and other chemical substances.

As we previously reported, the Newark plant environment has been and is very complex. The facility has undergone many physical changes over the past 50 years and some early production processes no longer exist. Furthermore, there are and have been many potential exposures in addition to fiberglass. For example, fiberglass based cements were first mixed at the Newark plant in 1935 on an experimental basis and were produced from 1936 to 1952 . At some time during the manufacture of insulating cements, asbestos was one of the product ingredients. Furthermore, there was more than one manufacturing location within the plant for cements over the time cements were produced.

The complexity of the manufacturing environment over time was such that use of a typical job title or average exposure was inadequate for an accurate description of any Newark plant employee's exposure experience. The extensive historical environmental reconstruction carried out for Newark was able to characterise successfully the exposure profile for workers in this study. It is the purpose of this paper not only to incorporate extended exposure profiles with information on smoking and other factors delineated in the interview survey but to describe the method for achieving those exposure profiles.

\section{Materials and methods}

Cases and controls were drawn from the historical cohort mortality study of production and maintenance workers employed at the Newark plant for at least one year between 1 January 1940 and 31 December 1962 and followed up to the end of 1982. This was carried out on behalf of the Thermal Insulation Manufacturers Association (TIMA). ${ }^{2}$ Cases are those for whom either malignant or non-malignant respiratory disease (excluding influenza and pneumonia) was the underlying cause of death as coded by a qualified nosologist according to the International Classification of Diseases revision in effect at the time of death. Potential controls were any member of the cohort who was not a case, but excluded, for ethical considerations, decedents whose cause of death was either suicide or homicide. Controls were matched on year of birth ( \pm two years) and survival to the end of follow up or death ( \pm two years) to allow for comparable time from initial exposure to death or end of follow up.

A personal interview survey obtained information on demographv (birthdate, race, education, marital 
state, parent's ethnic background, and place of birth), lifetime residence, occupational and smoking histories, hobbies, and personal and family medical history. A complete description of the survey method and results has been published. ${ }^{1}$

The historical environmental reconstruction incorporates a history of engineering processes of the facility including a written history of processes from 1938 to 1987 (the year the engineering history was undertaken) and a series of engineering drawings of the facility that depict major structural changes as well as process moves (building to building or within building). The final narrative is about 1000 pages long and contains 38 process chapters each with general information about the process and specific information related to batch, binder, environment, ventilation, and changes in processes both to equipment and to process constituents (substances, chemicals, etc). The narrative was developed from various historical documents plus extensive interviews with knowledgeable retirees. Documents included laboratory notebooks dating back to the early 1940 s, which detailed the early research and development activities at the plant; material and product specifications that provided information on customer purchase and acceptance standards; batch books (daily records by furnace of the batch composition) that provided information about some of the substances utilised in the plant; marketing and sales newsletters; plant newsletters; plant property inventories; expense authorisations dating back to 1941 that gave information about equipment purchases and rebuilds; production notebooks; microfilmed engineering drawings (some 50000 were reviewed for possible use in the Newark engineering history and plant plot plans).

A team of four Owens-Corning Fiberglas engineers had the primary responsibility for compiling the engineering history narrative with the Division being responsible for overseeing all aspects of the work. An interactive process between the Division and Owens-Corning Fiberglas continued for about 18 months before the engineering history was finalised. An audit of the materials used in compiling the Newark engineering history was conducted by the Division to ensure that the information contained in the engineering history narrative and engineering drawings accurately reflected the information available from historical sources.

The engineering drawings produced as a part of the process history provided a graphical representation of the growth of the plant site and the dynamic nature of the facility. The earliest blueprint (about 1921) depicts the layout of the plant when it was operated as a bottling plant by the Owens Bottling Company. From this time, blueprints of the plant were created for every year in which there were major physical changes to the facility or to depict changes in the location of processes within the various buildings.

Historical information on department names, job titles, and department and job codes was obtained from wage rate books and job promotion manuals. Wage rate books are the result of contractual compensation negotiations and contain official department and job titles back to 1941 . Job promotion manuals dating back to the late 1930 s provided a comprehensive listing of departments and job titles historically, as well as department and job numbers where available.

The employee work history provided the linkage between the individual employee and the historical environmental reconstruction. Individual work histories contain job titles, department names, start date for each job, and status (hire, terminations, leaves of absence, rate changes, etc). Each line of the work history for every case and control was entered into a computerised work history file and resulted in about 38000 entries. Each line of the work history was assigned a process code corresponding to the engineering history. Assignment of department to process code was blinded - that is, whether the subject was a case or a control was unknown to the coder.

Initial coding was done by assigning a department to a process chapter in the engineering history when the department name in the work history matched a process chapter in the engineering history. There were instances where a process encompassed several departments. For example, there was a single process chapter on wool insulation that included several departments from the forming end to the packing end. It was necessary to separate the forming end operation from the packing end operation to make sure that assignment of exposure was as specific as possible.

There were also instances where a department encompassed several processes and assignment to a process required referencing a department and job title combination from the work history. For example, in the early days of the plant the fabricating department encompassed several processes including sewn blankets, metal mesh blankets, and cements. The work history lists fabricating as the department whereas the job title indicates sewn blankets and this requires a referencing of the department and job title combination to achieve specificity in work assignments and potential exposures.

A list of substances (exposures) for each process was developed from information contained in the engineering history. Although industrial hygiene records exist from about 1970 onwards, there are few records for quantitative assessment of exposure for early processes. For those processes for which 
there is no modern counterpart, there is no basis for extrapolating historical exposure levels from current industrial hygiene data. Thus we established an exposure assessment committee to develop quantitative estimates of potential exposure to each substance for each process. The committee consisted of current and former Owens-Corning Fiberglas employees knowledgeable in industrial hygiene and the current and historical plant processes. Although several thousand substances were enumerated in the engineering history, assessment of potential exposure to substances other than respirable fibres and total particulate was limited to substances known or suspected to be carcinogens or respiratory irritants. These include asbestos, talc, asphalt fumes, formaldehyde, and silica.

The committee estimated exposure in each process for each of these substances by assigning each process to one of four ranges of estimated potential exposure (eight hour time weighted average (TWA)) specific for calendar time (table 1). This procedure resulted in estimates of the daily exposure to each of the substances over a worker's entire working lifetime. Cumulative exposure to each substance was developed for each employee as the product of the number of days in a process multiplied by the midpoint of the exposure range and summed over all processes. The cumulative

Table 1 Ranges of exposures used to estimate exposures to each substance for each process

\begin{tabular}{|c|c|c|}
\hline Level & Range & Midpoint \\
\hline \multicolumn{3}{|c|}{ Respirable fibres (fibres $/ \mathrm{ml}$ ): } \\
\hline 1 & $0.001-0.009$ & 0.005 \\
\hline 2 & $0.01-0.09$ & 0.05 \\
\hline 3 & $0.1-0.99$ & 0.5 \\
\hline 4 & $\geqslant 1$ & $5 \cdot 0$ \\
\hline \multicolumn{3}{|c|}{ Asbestos (fibres/ml): } \\
\hline 1 & $0.001-0.009$ & 0.005 \\
\hline 2 & $0.01-0.09$ & 0.05 \\
\hline 3 & $0 \cdot 1-0.99$ & 0.5 \\
\hline 4 & $\geqslant 1$ & $5 \cdot 0$ \\
\hline \multicolumn{3}{|c|}{ Talc (fibres $/ \mathrm{ml}$ ): } \\
\hline 1 & $0.001-0.009$ & 0.005 \\
\hline 2 & $0.01-0.09$ & 0.05 \\
\hline 3 & $0 \cdot 1-0.99$ & 0.5 \\
\hline 4 & $\geqslant 1$ & $5 \cdot 0$ \\
\hline \multicolumn{3}{|c|}{ Formaldehyde (ppm): } \\
\hline 1 & $0.01-0.09$ & 0.05 \\
\hline 2 & $0.1-0.49$ & 0.25 \\
\hline 3 & $0.5-0.99$ & $0 \cdot 75$ \\
\hline 4 & $\geqslant 1$ & 1.5 \\
\hline \multicolumn{3}{|c|}{ Respirable silica $\left(\mathrm{mg} / \mathrm{m}^{3}\right)$ : } \\
\hline 1 & $0.001-0.009$ & 0.005 \\
\hline 2 & $0.01-0.09$ & 0.05 \\
\hline 3 & $0 \cdot 1-0.49$ & $0 \cdot 25$ \\
\hline 4 & $\geqslant 0.5$ & $1 \cdot 0$ \\
\hline \multicolumn{3}{|c|}{ Asphalt fumes $\left(\mathrm{mg} / \mathrm{m}^{3}\right)$ : } \\
\hline 1 & $0.005-0.015$ & 0.01 \\
\hline \multicolumn{3}{|c|}{ Total particulate $\left(\mathrm{mg} / \mathrm{m}^{3}\right)$ : } \\
\hline 1 & $<0.49$ & $0 \cdot 25$ \\
\hline 2 & $0.50-1.99$ & $1 \cdot 00$ \\
\hline 3 & $2 \cdot 00-4.99$ & 3.5 \\
\hline 4 & $\geqslant 5$ & $7 \cdot 5$ \\
\hline
\end{tabular}

exposures (days) were then arrayed for each substance and the array divided by the exposure assessment committee into the ranges used for analysis. Table 2 shows the number of cases and controls by cumulative exposure (days) for each of the substances in the analysis.

Because $93 \%$ of the cases of malignant respiratory disease were lung cancers, the current analysis focuses on lung cancer and non-malignant respiratory disease. Initial analyses assessed the association between lung cancer or non-malignant respiratory disease and each of the individual variables obtained from the interview survey (birthplace, education, income, marital state, smoking for six months or more, age first started smoking and duration of smoking), the historical environmental reconstruction (cumulative exposure to asphalt, talc, silica, asbestos, formaldehyde, respirable fibres, and total particulate), and employment histories (year of hire, duration of employment, age at first hire). The maximum number of lung cancer cases available for matched analysis of interview data was 144 (260 controls) and for non-malignant respiratory disease it was 101 (183 controls).

Matched, unadjusted odds ratios (ORs) were produced for each of the variables. Conditional logistic regression was then carried out to estimate the effect of any one variable while controlling for the effect of all the others. ${ }^{3}$ This analysis entered interview and employment variables with ORs of 1.5 or more or 0.67 or less regardless of whether they were significant. Exposure variables were entered without regard to significance or direction of the ORs. It was intended that the final regression model would use significant variables from the first step. Matched analyses are presented to be certain to account for the relation between the matching variables and outcome.

\section{Results}

Adjusted ORs for subject characteristics obtained at interview have been presented previously. ${ }^{1}$ For lung cancer, there were statistically significant ORs for smoking $(O R=14.7)$ and one of the education categories from the interview data. Table 3 shows the unadjusted, matched ORs for employment characteristics and cumulative exposure to respirable fibres, asbestos, talc, formaldehyde, silica, asphalt fumes, and total particulate. Among the employment characteristics there were statistically significant ORs for year of hire and age at first hire. For those hired before 1945 , the OR was $2 \cdot 177$ (95\% confidence interval (95\% CI) $1 \cdot 386-3 \cdot 421)$ compared with those hired after 1945 . Those hired at ages 35 and over had an OR of 0.298 (95\% CI $0 \cdot 154-0.572$ ) compared with those hired at ages less than 35. Cases and controls were not differenti- 
Table 2 Cases and controls by cumulative exposure levels (days) for exposures used in logistic regression analyses

\begin{tabular}{|c|c|c|c|c|c|c|}
\hline \multirow[b]{2}{*}{ Level } & \multicolumn{3}{|l|}{ Lung cancer } & \multicolumn{3}{|c|}{ Non-Malignant respiratory disease } \\
\hline & Range & Cases & Controls & Range & Cases & Controls \\
\hline $\begin{array}{l}\text { Respirable fibres (fibres/ml): } \\
1 \text { (referent group) } \\
3\end{array}$ & $\begin{array}{l}<100 \\
\quad 100-299.99 \\
\geqslant 300 \\
(\text { maximum }=1348 \cdot 6)\end{array}$ & $\begin{array}{l}98 \\
37 \\
27\end{array}$ & $\begin{array}{l}236 \\
60 \\
67\end{array}$ & $\begin{aligned} &< 100 \\
& 100-299 \cdot 99 \\
& \geqslant 300 \\
&(\operatorname{maximum}=1443 \cdot 8)\end{aligned}$ & $\begin{array}{l}70 \\
23 \\
18\end{array}$ & $\begin{array}{l}159 \\
62 \\
41\end{array}$ \\
\hline $\begin{array}{l}\text { Asbestos (fibres/ml): } \\
1 \text { (referent group) } \\
2 \\
3 \\
4\end{array}$ & $\begin{array}{l}\quad 0 \\
0 \cdot 01-0 \cdot 999 \\
1 \cdot 0-99 \\
\geqslant 100 \\
(\text { maximum }=2503 \cdot 0)\end{array}$ & $\begin{array}{l}43 \\
37 \\
79 \\
3\end{array}$ & $\begin{array}{l}98 \\
76 \\
176 \\
13\end{array}$ & 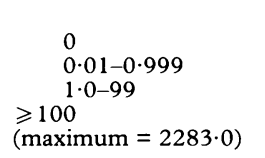 & $\begin{array}{l}34 \\
22 \\
50 \\
5\end{array}$ & $\begin{array}{l}75 \\
53 \\
127 \\
7\end{array}$ \\
\hline $\begin{array}{l}\text { Talc (fibres/ml): } \\
1 \text { (referent group) } \\
2 \\
3\end{array}$ & $\begin{array}{l}0 \\
10-999 \\
\geqslant 1000 \\
(\text { maximum }=54962 \cdot 5)\end{array}$ & $\begin{array}{l}138 \\
14 \\
10\end{array}$ & $\begin{array}{l}284 \\
50 \\
29\end{array}$ & $\begin{array}{c}0 \\
10-999 \\
\geqslant 1000 \\
(\text { maximum }=44145 \cdot 0)\end{array}$ & $\begin{array}{l}92 \\
12 \\
7\end{array}$ & $\begin{array}{l}222 \\
24 \\
16\end{array}$ \\
\hline $\begin{array}{l}\text { Formaldehyde (ppm): } \\
1 \text { (referent group) } \\
2 \\
3 \\
4\end{array}$ & $\begin{array}{l}0 \\
0 \cdot 25-99 \cdot 99 \\
100-999 \\
\geqslant 1000 \\
(\text { maximum }=17076)\end{array}$ & $\begin{array}{l}24 \\
56 \\
51 \\
31\end{array}$ & $\begin{array}{l}53 \\
122 \\
130 \\
58\end{array}$ & $\begin{array}{l}0 \\
0 \cdot 25-99 \cdot 99 \\
100-999 \\
\geqslant 1000 \\
(\text { maximum }=15783 \cdot 6)\end{array}$ & $\begin{array}{l}24 \\
26 \\
45 \\
16\end{array}$ & $\begin{array}{l}54 \\
78 \\
86 \\
44\end{array}$ \\
\hline $\begin{array}{l}\text { Respirable silica }\left(\mathrm{mg} / \mathrm{m}^{3}\right) \text { : } \\
1 \text { (referent group) } \\
2 \\
3 \\
4 \\
5\end{array}$ & $\begin{array}{l}0 \\
0 \cdot 01-0 \cdot 999 \\
1-9 \cdot 9 \\
10-99 \cdot 9 \\
\geqslant 100 \\
\text { (maximum = 1799.9) }\end{array}$ & $\begin{array}{l}38 \\
24 \\
58 \\
36 \\
6\end{array}$ & $\begin{array}{l}83 \\
56 \\
124 \\
87 \\
13\end{array}$ & $\begin{array}{l}0 \\
0.01-.999 \\
1-9 \cdot 9 \\
10-99 \cdot 9 \\
\geqslant 100 \\
(\text { maximum }=1438 \cdot 7 \text { ) }\end{array}$ & $\begin{array}{l}24 \\
20 \\
34 \\
28 \\
5\end{array}$ & $\begin{array}{l}64 \\
41 \\
76 \\
72 \\
9\end{array}$ \\
\hline $\begin{array}{l}\text { Asphalt fumes }\left(\mathrm{mg} / \mathrm{m}^{3}\right) \text { : } \\
1 \text { (referent group) }\end{array}$ & $\begin{array}{l}0 \\
\geqslant 0.01 \\
(\text { maximum }=118.6)\end{array}$ & $\begin{array}{l}51 \\
111\end{array}$ & $\begin{array}{l}112 \\
251\end{array}$ & $\begin{array}{l}0 \\
\geqslant 0 \cdot 01 \\
(\text { maximum }=120 \cdot 9)\end{array}$ & $\begin{array}{l}32 \\
79\end{array}$ & $\begin{array}{l}91 \\
171\end{array}$ \\
\hline $\begin{array}{l}\text { Total particulate }\left(\mathrm{mg} / \mathrm{m}^{3}\right) \text { : } \\
1 \text { (referent group) } \\
3\end{array}$ & $\begin{array}{c}0-999 \\
1000-4999 \\
\geqslant 5000 \\
(\text { maximum }=52476 \cdot 2)\end{array}$ & $\begin{array}{l}60 \\
57 \\
45\end{array}$ & $\begin{array}{l}122 \\
129 \\
112\end{array}$ & $\begin{array}{c}0-999 \\
1000-4999 \\
\geqslant 5000 \\
(\text { maximum }=38758 \cdot 0)\end{array}$ & $\begin{array}{l}43 \\
40 \\
28\end{array}$ & $\begin{array}{l}105 \\
90 \\
67\end{array}$ \\
\hline
\end{tabular}

ated by duration of employment. There were no statistically significant increases in ORs for lung cancer for any exposure when analysed individually. Furthermore, there was no pattern of increasing ORs with increasing exposure that would suggest an association with any of the exposures considered.

For non-malignant respiratory disease, only the smoking variables were significant among the personal characteristics determined at interview. ${ }^{1}$ As can be seen from table 3, none of the ORs for employment characteristics or any of the exposure variables were statistically significant. The univariate results were, however, in the opposite direction from those for lung cancer for both year of hire $(\mathrm{OR}=0.955,95 \%$ CI $0.596-1.529)$ and age at first hire (OR $=1 \cdot 46,95 \%$ CI 0.719-2.963). For cumulative exposure to asbestos, silica and asphalt fumes, the highest $\mathrm{OR}$ was associated with the highest exposure level. There is no pattern of consistently increasing ORs with cumulative exposure except for asphalt fumes.

Table 4 shows the results of the conditional logistic regression analyses. As indicated, statistical- ly significant variables or those giving an $O R \geqslant 1.5$ or $\leqslant 0.67$ for personal interview or employment history variables plus all exposure variables except total particulate were included in the models. Separate analyses were run for total particulate since this variable represents a combination of exposures. Six personal interview or employment characteristic variables (place of birth, education, income, and smoking state, year of hire, and age at first hire) met the inclusion criteria for lung cancer. For reasons described earlier, place of birth and income were excluded from the final model. ${ }^{1}$ The final lung cancer models included smoking, education, year of hire, age at first hire, and the six exposure variables. In these models, among the personal interview characteristics or employment history variables, only smoking (OR $=26 \cdot 17,95 \%$ CI $3 \cdot 316-206 \cdot 5)$ and age at first hire $(\mathrm{OR}=0 \cdot 244$, $95 \%$ CI $0.083-0 \cdot 717$ ) were statistically significant when all variables were simultaneously adjusted for. There was a raised but not significant $O R=1.944$ $(95 \%$ CI $0 \cdot 851-4 \cdot 445)$ for those hired before 1945 . None of the exposure variables showed statistically significant increases in ORs for lung cancer. Also, 
Table 3 Matched, unadjusted lung cancer and non-malignant respiratory disease ORs for risk factors determined by employment history or historical environmental reconstruction

\begin{tabular}{|c|c|c|}
\hline & Lung cancer & Non-malignant respiratory disease \\
\hline & OR $(95 \% C I)$ & OR $(95 \% C I)$ \\
\hline \multicolumn{3}{|c|}{$\begin{array}{l}\text { Employment characteristics: } \\
\text { Year of hire: }\end{array}$} \\
\hline $\begin{array}{l}1945 \text { or later } \\
\text { before } 1945\end{array}$ & $\begin{array}{l}1.000 \\
2 \cdot 177(1.386-3.421)\end{array}$ & $\begin{array}{l}1.000 \\
0.955(0.596-1.529)\end{array}$ \\
\hline \multicolumn{3}{|c|}{ Duration of employment $(y)$ : } \\
\hline $\begin{array}{l}5 \text { or more } \\
\text { Less than } 5\end{array}$ & $\begin{array}{l}1.000 \\
1.107(0.761-1.612)\end{array}$ & 1.000 \\
\hline \multicolumn{3}{|l|}{ Age at first hire (y): } \\
\hline $\begin{array}{l}\text { Less than } 35 \\
35 \text { and over }\end{array}$ & $\begin{array}{l}1.000 \\
0.298(0 \cdot 154-0.574)\end{array}$ & $\begin{array}{l}1.000 \\
1.460(0.719-2.963)\end{array}$ \\
\hline \multicolumn{3}{|c|}{ Exposure variables (cumulative exposure to): } \\
\hline \multicolumn{3}{|c|}{ Respirable fibres (fibres $/ \mathrm{ml}$ ): } \\
\hline$<100$ & 1.000 & \\
\hline $\begin{array}{l}100-299 \cdot 99 \\
>300\end{array}$ & $\begin{array}{l}1.430(0.900-2.272) \\
0.945(0.557-1.605)\end{array}$ & $\begin{array}{l}0.850(0.494-1.461) \\
0.984(0.524-1.850)\end{array}$ \\
\hline \multicolumn{3}{|l|}{ Asbestos (fibres/ml): } \\
\hline 0 & 1.000 & 1.000 \\
\hline $\begin{array}{l}0.01-0.999 \\
1.0-99\end{array}$ & $\begin{array}{l}1.123(0.647-1.947) \\
1.016(0.648-1.593)\end{array}$ & $\begin{array}{l}0.900(0.475-1.705) \\
0.874(0.524-1.458)\end{array}$ \\
\hline$>100$ & $0.553(0.152-2.007)$ & $1.585(0.479-5.245)$ \\
\hline \multirow{2}{*}{\multicolumn{3}{|c|}{ Talc (fibres $/ \mathrm{ml}$ ): }} \\
\hline & 1.000 & \\
\hline 10-999 & $0.551(0.293-1.038)$ & $1.318(0.621-2.798)$ \\
\hline$\geqslant 1000$ & $0.678(0.314-1.466)$ & $1.178(0.461-3.010)$ \\
\hline \multicolumn{3}{|l|}{ Formaldehyde (ppm): } \\
\hline & 1.000 & 1.000 \\
\hline $0.25-99.99$ & $1.003(0.554-1.819)$ & $0.728(0.376-1.409)$ \\
\hline $100-999$ & $0.803(0.446-1.444)$ & $1.173(0.657-2.093)$ \\
\hline$\geqslant 1000$ & $1.183(0.600-2 \cdot 336)$ & $0.801(0.370-1.734)$ \\
\hline \multicolumn{3}{|c|}{ Respirable silica $\left(\mathrm{mg} / \mathrm{m}^{3}\right)$ : } \\
\hline 0 & 1.000 & 1.000 \\
\hline $0.01-.999$ & $0.947(0.512-1.753)$ & $1.358(0.651-2.831)$ \\
\hline $1-9.9$ & $0.994(0.599-1.647)$ & $1.246(0.654-2.376)$ \\
\hline $10-99 \cdot 9$ & $0.875(0.508-1.505)$ & $1.080(0.562-2.073)$ \\
\hline$\geqslant 100$ & $1.003(0.348-2 \cdot 897)$ & $1.914(0.538-6.802)$ \\
\hline \multicolumn{3}{|c|}{ Asphalt fumes $\left(\mathrm{mg} / \mathrm{m}^{3}\right)$ : } \\
\hline 0 & $1 \cdot 000$ & $1 \cdot 000$ \\
\hline$\geqslant 0.01$ & $0.962(0.653-1.417)$ & $1.340(0 \cdot 815-2 \cdot 204)$ \\
\hline \multicolumn{3}{|c|}{ Total particulate $\left(\mathrm{mg} / \mathrm{m}^{3}\right)$ : } \\
\hline 0-999 & $1 \cdot 000$ & 1.000 \\
\hline $1000-4999$ & $0.873(0.556-1.372)$ & $1.085(0.657-1.791)$ \\
\hline$\geqslant 5000$ & $0.802(0.504-1.278)$ & $1.044(0.589-1.849)$ \\
\hline
\end{tabular}

we found no consistent pattern of increasing ORs with increasing exposure for respirable fibres, asbestos, formaldehyde, or respirable silica exposure. For both talc (OR $=1.355,95 \%$ CI $0 \cdot 407-4.515)$ and asphalt fumes $(\mathrm{OR}=1 \cdot 131,95 \%$ CI $0 \cdot 468-2 \cdot 730$ ), the higher ORs were associated with the higher exposures.

For non-malignant respiratory disease, none of the employment history variables were statistically significant, nor did they meet the criteria for inclusion. Only the smoking variable showed a statistically significant increase (OR $=2.589,95 \%$ CI $1 \cdot 199-5 \cdot 590)$ in the univariate analysis. Although both income and marital state met the conditional logistic regression model inclusion criteria, income was excluded from the final model because of the many unknowns for this variable. For non-malignant respiratory disease, the final model included smoking, marital state, and each of the six exposure variables. In this model, only the smoking variable was statistically significant $(\mathrm{OR}=2 \cdot 637,95 \% \mathrm{CI}$ 1.146-6.069). Although none of the exposure variables produced significant ORs, higher ORs were found for the higher ranked exposure levels for respirable fibres, asbestos, silica and asphalt fumes. For exposure to silica, the ORs were more than double for exposures up to $99.9 \mathrm{mg} / \mathrm{m}^{3}$ days and for cumulative exposures $\geqslant 100 \mathrm{mg} / \mathrm{m}^{3}$, the $\mathrm{OR}$ was $3.247(95 \%$ CI $0.544-19 \cdot 40)$. The OR for asphalt fumes for exposures $\geqslant 0.01 \mathrm{mg} / \mathrm{m}^{3}$ days was 2.071 (95\% CI 0.743-5.776).

\section{Discussion}

Historical cohort studies, conducted both in the United States ${ }^{24}$ and in seven European countries ${ }^{5}$ that considered the issue of risk of lung cancer among workers engaged in the production of man made mineral fibres have shown statistically significant increases for these workers based on national 
Table 4 Lung cancer and non-malignant respiratory disease adjusted ORs from conditional logistic regression analysis for risk factors determined by interview, employment history, or historical environmental reconstruction

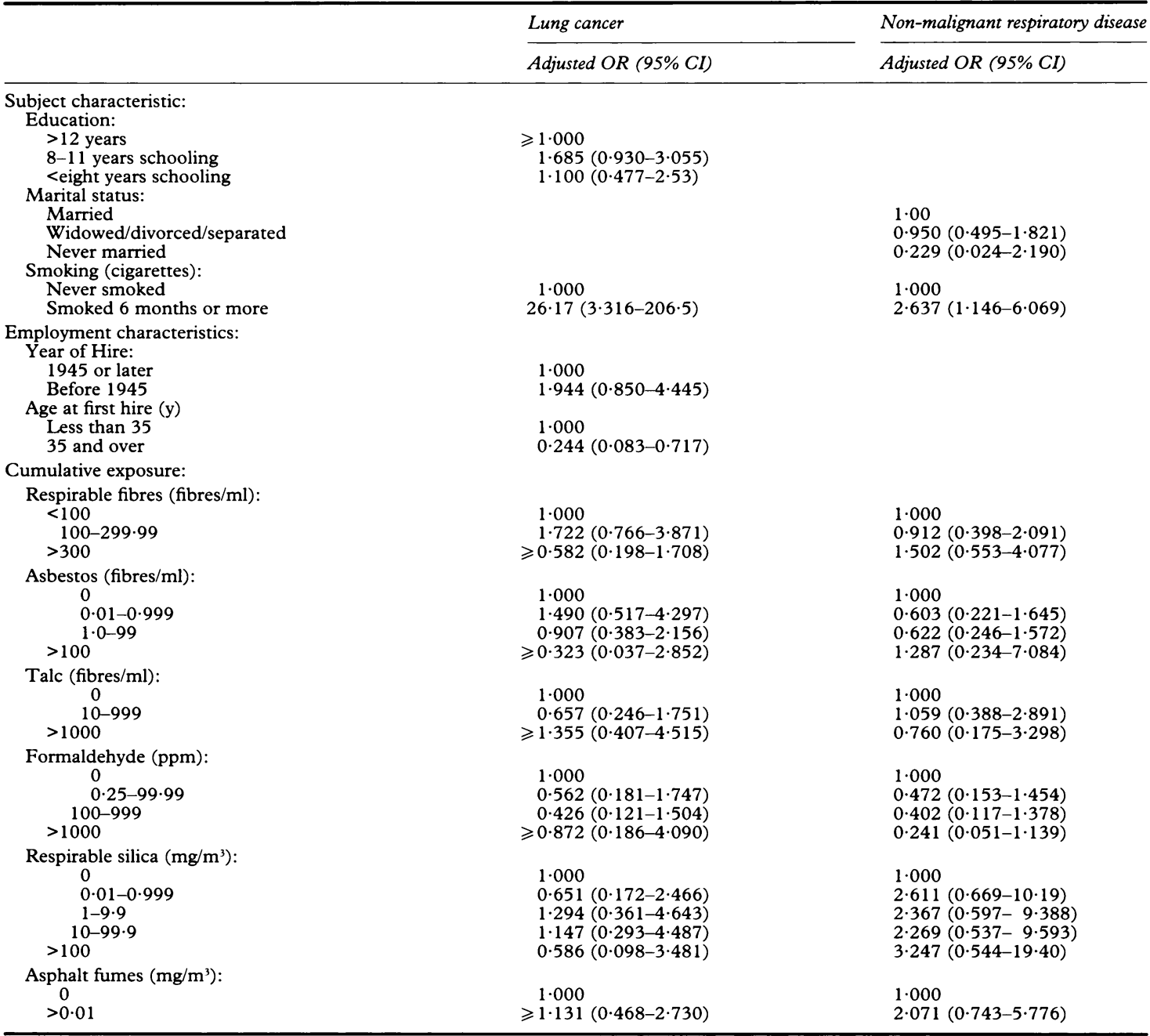

death rates. Results of these studies were not adjusted for the possible confounding effects of smoking and other personal characteristics or for exposures other than respirable fibre.

The Newark plant constitutes $38 \%$ of all man made mineral fibre workers in the TIMA study. The current case-control study was undertaken to determine the extent to which exposures to substances in the Newark plant environment, to nonworkplace factors, or to a combination may play a part in risk of mortality from respiratory disease among workers in this plant. Information was obtained on demographic and personal characteristics (including smoking), Owens-Corning Fiberglas employment characteristics (duration of employment, year of hire, age at first hire) and on cumulative exposure to respirable fibres, asbestos, talc, formaldehyde, silica, and asphalt fumes.

Only the variables smoking and age at first hire were statistically significant in the conditional logistic regression analysis for lung cancer. There was, however, an increased OR for those hired before 1945. Although none of the exposure variables resulted in a significantly increased OR, both talc and asphalt fumes showed increased ORs for higher cumulative exposures. Corollary analyses that entered the interview and employment history variables with the exposures one at a time consistently 
showed that smoking and age at first hire were the only statistically significant variables for lung cancer and in none of the models was there a significant interaction between smoking and any of the above exposures.

The results of this study, with respect to respirable fibres and mortality from lung cancer, are consistent with the results of Enterline, et al in 1987. They conducted a case-referent study on the entire TIMA cohort and reported the results of a logistic regression analysis for respiratory cancer among the fibrous glass workers. They entered into their model the variables year of birth, age at termination of the study (1982) or at death, smoking, time weighted cumulative exposure, and an interaction term between smoking and exposure to fibre. "Year of birth, age, and smoking were the only variables that were statistically significant in this analysis." "Furthermore, table 18 of that paper gives a maximum likelihood estimate of the log OR for smoking among fibrous glass workers of over 14 , consistent with that reported here.

The results for non-malignant respiratory disease are somewhat different from those for lung cancer. The results of the conditional logistic regression analysis for risk factors determined by interview, employment history, or historical environmental reconstruction (table 4) show smoking as the only statistically significant variable. There are, however, increased ORs for the higher cumulative exposure categories for respirable fibres, asbestos, silica, and asphalt fumes. For both silica and asphalt fumes, ORs were more than double the reference groups for all exposure categories.

One potential complicating factor in the analysis of these data for non-malignant respiratory disease is the fact that there were eight deaths with silicosis coded as the underlying cause. Of the eight, two had no exposure to silica at Newark. One of these subjects was known to have had silicosis some time before his original hire date at Newark. The source of the other's exposure to silica is unclear. The conditional logistic regression analysis was rerun with these two subjects and their controls removed and the results were similar to those in table 4 . The ORs were greater than 2 for exposures up to 99.9 $\mathrm{mg} / \mathrm{m}^{3}$ days and greater than 3 for exposure $\geqslant 100$ $\mathrm{mg} / \mathrm{m}^{3}$ days even with the two subjects who died from silicosis removed.

Smoking was the only statistically significant variable in the conditional logistic regression analysis for non-malignant respiratory disease and the increased ORs for the substances mentioned may represent the results of a random process. On the other hand, they could suggest the possibility of a relation between exposure to these substances in the plant environment and non-malignant respiratory disease even after adjustment for smoking.
Of special interest in the evaluation of whether exposure to glass fibres contributes to lung cancer or non-malignant respiratory disease risk is the question of fine fibres. There has been some confusion in earlier published work, about the ability to identify employees with exposure to fine fibre and the role of pilot plant operations in that exposure. The historical environmental reconstruction has shown that potential for exposure to fine fibre began as early as the late 1930 s as a pilot operation. Pilot plant or laboratory operations began at the Newark plant in 1934. The pilot plant (or the experimental manufacturing department as it was called for some time) was an administrative term for a variety of operations run in various locations and manufacturing lines throughout the plant and was not located in one specific building. Whether or not a line was a pilot or a manufacturing operation depended on whether the laboratory division or the manufacturing division had administrative responsibility.

The Newark historical environmental reconstruction text lists 95 pilot operations including work on various applications for larger fibre diameter wool insulation, textile operations, and marble making processes. One of the pilot operations conducted at Newark in the 1940s was fine fibre. Fine fibre was produced using the flame attenuated fibrisation process with an average fibre diameter of 1 to $3 \mu$. The material was produced commercially (in the Aerocor department) at Newark during the late 1940s until 1950 when the production process was transferred to another Owens-Corning Fiberglas manufacturing location.

Even though the fine fibre operation began as a pilot operation, not everyone who worked in pilot operations worked in fine fibres. To identify those with exposure to fine fibre operations, work histories were reviewed from a listing of department and job title combinations prepared by Owens-Corning Fiberglas in $1975 .{ }^{\circ}$ Department and job title with exposure to fine fibre were:

(1) Pilot plant (1940 to November 1949): "A" fibre machine regardless of job title; any job title with "SF" as prefix or suffix; any job title including "A" fibre; silica fibre treater or tester; (2) Aerocor (before 1 April 1950): any job title; (3) Works Laboratory: "SF" quality control tester, inspector; (4) Textile pilot plant (1 August 1945 to 1 January 1946): staple fibre.

A total of 44 subjects had exposure to fine fibre processes (10 lung cancer cases, 10 non-malignant respiratory disease cases, and 24 controls) and these were subjected to a separate analysis. Those with a cumulative exposure of $<100 \mathrm{fibre} / \mathrm{ml}$ days were assigned to the referent group for comparison with those with $\geqslant 100$ cumulative fibre/ml days of exposure to fine fibres. An unmatched analysis was 
Table 5 Unmatched, unadjusted lung cancer and non-malignant respiratory disease ORs among those who had ever worked in fine fibre

\begin{tabular}{|c|c|c|}
\hline & $O R$ & $(95 \% C I)$ \\
\hline $\begin{array}{l}\text { Fine fibres (fibres } / \mathrm{ml} \text { ) } \\
\quad<100 \\
\geqslant 100\end{array}$ & $\begin{array}{l}\text { Lung } \\
1.000 \\
1.000\end{array}$ & Lung cancer \\
\hline Fine fibres (fibres/ml) & \multicolumn{2}{|c|}{ Non-malignant respiratory disease } \\
\hline $\begin{array}{l}\text { Fine fibres (fibres } / \mathrm{ml} \text { ) } \\
\quad<100 \\
\geqslant 100\end{array}$ & $\begin{array}{l}1.000 \\
1.500\end{array}$ & $(0.336-6 \cdot 702)$ \\
\hline
\end{tabular}

carried out for those with experience in fine fibres with a single control group for both lung cancer and non-malignant respiratory disease. A comparison of the distributions of lung cancer cases and non-malignant respiratory disease with respect to year of birth and whether they survived with those of the controls showed that the distributions were similar even without matching.

The scarcity of cases and controls limits the extent to which analyses for fine fibre may be carried out. Within those limitations, table 5 shows that amorg those who had worked in fine fibre, the unadjusted, unmatched lung cancer OR was 1 (95\% CI $0 \cdot 229-4 \cdot 373)$ and for non-malignant respiratory disease, the OR was $1.5 \quad(95 \%$ CI $0 \cdot 336-6 \cdot 702$ ). There were four cases (three lung cancer and one non-malignant) and six controls for whom smoking information was not available making adjustment for this or other interview variables unreliable. The unadjusted lung cancer OR for exposure to fine fibre is consistent with that for all respirable fibres and does not suggest an association. For non-malignant respiratory disease, however, the unadjusted OR for fine fibre is opposite in direction from those for all respirable fibres. Within the limitations of the available data on fine fibre, there is no suggestion in these data that exposure to fine fibre has resulted in an increase in risk of lung cancer. The raised OR for non-malignant respiratory disease is inconclusive but warrants further investigation.

The question of whether fibreglass is carcinogenic has been investigated extensively. In general, information has been lacking with respect to a complete description of the working environment or the personal characteristics of the working population including smoking habits. The results of our investigation clearly indicate that for this population in this place and time, neither respirable fibres nor any of the substances investigated as part of the plant environment are statistically significant factors for lung cancer risk although there are increased ORs for exposure to talc and asphalt fume. It is clear that smoking is the most important factor for lung cancer risk in this population.

The situation is less clear for non-malignant respiratory disease. Unlike lung cancer, non-malignant respiratory disease represents a constellation of outcomes and not a single well defined end point. Although smoking was the only statistically significant factor for non-malignant respiratory disease in this analysis, the ORs for respirable fibres, asbestos, silica, and asphalt fumes were greater than unity for the highest exposure categories. Although the raised ORs for these substances may represent the results of a random process, they may be suggestive of an increased risk and require further investigation.

This study was supported by a grant to Georgetown University from the Owens-Corning Fiberglas Corporation. We gratefully acknowledge the contributions of Jon Konzen, Jon Amsel, Charles Axten, Richard Miller, Robert Holler, Don Eberts, Robert Venia, Gerald Devitt, Valerie Biggs, and members of the advisory committee-Dr Patricia A Buffler, University of California, Berkeley, Dr John Higginson, Georgetown University, and Dr Genevieve Matanoski, Johns Hopkins University School of Hygiene and Public Health.

Requests for reprints to: Dr Leonard Chiazze, Jr, Professor and Director, Division of Biostatistics and Epidemiology, Georgetown University School of Medicine, Kober Cogan, Room 409, Washington, DC 20007, USA.

1 Chiazze L, Watkins DK, Fryar C. A case-control study of malignant and non-malignant respiratory disease among employees of a fibreglass manufacturing facility. $\mathrm{Br} \mathcal{F}$ Ind Med 1992;49:326-33.

2 Enterline PE, Marsh G, Henderson V, Callahan C. Mortality update of a cohort of US man-made mineral fibre workers. Ann Occup Hyg 1987;31:625-56.

3 Breslow, NE, Day, NE. Statistical methods in cancer research, Vol 1. The analysis of case-control studies. Lyon: International Agency for Research on Cancer, 1980.

4 Enterline PE, Marsh GM, Esmen NA. Respiratory disease among workers exposed to man-made mineral fibers. $A m$ Rev Respir Dis 1983;128:1-7.

5 Simonato L, Fletcher AC, Cherrie JW: The International Agency for Research on Cancer historical cohort study of MMMF production workers in seven European countries extension of the follow-up. Ann Occup Hyg 1987;31:603-23.

6 Letter dated 21 May 1975 from Dr Jon L Konzen, OwensCorning Fiberglas Corporation, Toledo, Ohio to $\mathrm{Mr}$. David Bayliss, National Institute for Occupational Safety and
Health, Cincinnati, Ohio.

Accepted 19 October 1992 